\title{
The Influence of Allogenic Mesenchymal Stem Cells on the Hematological Status of Horses
}

Sarah Broeckx ${ }^{1}$, Rudy Forier ${ }^{2}$, Tom Mariën ${ }^{3}$, Marc Suls ${ }^{4}$, Vuk Savkovic ${ }^{5}$, Alfredo Franco-Obregón ${ }^{6}$, Luc Duchateau and Jan H Spaas ${ }^{1 *}$

${ }^{1}$ Global Stem cell Technology (GST), Geeneindestraat 1, B-3560 Meldert-Lummen, Belgium

${ }^{2}$ Wijvestraat $1 A, B-3520$ Zonhoven, Belgium

${ }^{3}$ Equitom Equine Hospital, Venusbergstraat 1, B-3560 Meldert-Lummen, Belgium

${ }^{4}$ Equine Veterinary Practice Dr Suls, Kazernelaan 144, NL-6006 SP Weert, The Netherlands

${ }^{5}$ Translational Centre for Regenerative Medicine, University of Leipzig, Philipp-Rosenthal-Strasse 55, D-04103 Leipzig, Germany

${ }^{6}$ Department for Biomechanics, ETH Zurich, Schafmattstrasse 30, Zurich, Switzerland

${ }^{7}$ Department of Comparative Physiology and Biometrics, Faculty of Veterinary Medicine, Ghent University, Salisburylaan 133, B-9820 Merelbeke, Belgium

\begin{abstract}
Background: It has been reported that mesenchymal stem cells (MSCs) have homing capacities after an intravenous injection and immunomodulating effects in vitro. However, there are no reports on their effect on the animal's hematological status.
\end{abstract}

Methods: Therefore, MSCs were isolated and characterized from a 4-years-old donor horse after having tested his blood on a wide range of transmittable diseases. Then, 6 horses (13- to 15-years-old) received a single injection into the jugular vein: 3 with MSCs and 3 with the carrier fluid consisting of DMEM and 10\% of DMSO. Multiple blood samples were taken at different time points at the same time of the day: before the intravenous MSC (Veno-Cell $\left.{ }^{\circledR}\right)$ injection $\left(T_{0}\right)$ and 1 day $\left(T_{1}\right), 1$ week $\left(T_{2}\right), 3$ weeks $\left(T_{3}\right)$ and 2 months $\left(T_{4}\right)$ after the treatment.

Results: In the control group no considerable changes were noticed over time, whereas, in all the treated horses, the baseline adjusted cortisol levels $(P=0.0490)$ and number of neutrophils $(P=0.0042)$ were significantly higher and glucose levels significantly lower $(P=0.033)$. At time point $T_{1}$, baseline adjusted blood thrombocyte levels were significantly higher in the treated group as compared to the control group $(P<0.0001)$. On the other hand, baseline adjusted basophils, eosinophils, lymphocytes and monocytes remained approximately the same in all the horses regardless the treatment. Additionally, the levels of total protein, albumin, alkaline phosphatase and all the tested minerals were not influenced by the injections.

Conclusion: In all patients consistent alterations in hematological parameters were noticed after intravenous allogenic MSC treatment. However, further research is warranted in order to verify what the exact influence of these changes might be on the animal's metabolism, general condition and performance ability.

Keywords: Stem cells; Blood; Horse; Veno-Cell ${ }^{\circledR}$

\section{Introduction}

The intravenous application of human mesenchymal stem cells (MSCs) has been previously reported to restore the hearing in guinea pigs [1] and to prevent transplant rejection [2]. Moreover, intravenous injection of a mixture of autologous MSCs and hematopoietic stem cells has been reported to improve multiple sclerosis (MS) symptoms in humans [3], improve ophthalmological diseases in horses [4] and they could be used safely in equine dermatological [5] and tendon pathologies [6]. Besides the homing capacities of MSCs, different in vitro immunomodulatory effects have been described, such as the regulation of lymphopoiesis and suppression of the immune system [7].

Nevertheless, autologous MSC treatment is not always feasible under field practice, sample sterility depends on the practitioner and donor influences are difficult to control. Moreover, sometimes the sample isolation takes so long that it postpones injection and even compromises the treatment. Another concern is the quality of the MSCs, because most of the individuals that require such autologous treatment are in fact elderly patients and it has been reported that they yield less potent stem cells [8]. Indeed, stem cells of elderly human donors do not only have a significantly lower proliferative and migratory potential, but also a lower differentiation capacity [8]. It would be advisable to characterize each MSC isolate before each clinical application, however, this is highly cost-generating and time- consuming and not always feasible. For all the above stated reasons, this study focuses on the use of allogenic MSCs of a young donor with young MSCs. Indeed, the safe use of allogenic multipotent MSCs has been described in different independent human and equine studies [914]. In this regard, therapy-resistant graft-versus-host diseases have been successfully treated in human patients $[13,15]$.

Still, to our knowledge, there are no reports on the effect of allogenic MSCs on the hematological status of an animal. Such findings would be of importance for a better comprehension of how MSCs in vivo regulate the immune system after intravenous application. Therefore, the goal of the present study was to study the influence of a single intravenous injection of young allogenic peripheral blood (PB)-derived MSCs (Veno-Cell ${ }^{\circledR}$ ) on different hematological parameters of elderly acceptors.

*Corresponding author: Jan H Spaas, Global Stem cell Technology (GST), Geeneindestraat 1, B-3560 Meldert-Lummen, Belgium, Tel: +32 135561 06; Fax: +32 135561 07; E-mail: janspaas@gst.be

Received March 19, 2013; Accepted April 29, 2013; Published May 01, 2013

Citation: Broeckx S, Forier R, Mariën T, Suls M, Savkovic V, et al. (2013) The Influence of Allogenic Mesenchymal Stem Cells on the Hematological Status of Horses. J Stem Cell Res Ther 3: 136. doi:10.4172/2157-7633.1000136

Copyright: (c) 2013 Broeckx S, et al. This is an open-access article distributed under the terms of the Creative Commons Attribution License, which permits unrestricted use, distribution, and reproduction in any medium, provided the original author and source are credited. 


\section{Materials and Methods}

\section{Isolation of mesenchymal stem cells (MSCs)}

In total $50 \mathrm{ml}$ of blood was collected in sterile EDTA tubes from the vena jugularis of the 4-years-old donor gelding for mesenchymal stem cell (MSC) isolation. At the same time serum was collected and sent to Böse laboratory (Harsum, Germany) for testing on different transmittable diseases as previously reported by our group [10]. Then, the blood was centrifuged at $1000 \mathrm{G}$ for 20 minutes and the buffy coat was collected and diluted 1:2 in phosphate buffered saline (PBS) 1x. Afterwards, this suspension was gently layered on an equal amount of Percoll $^{\circledR}$ density gradient (GE Healthcare). The further isolation was performed as previously described [10]. After that, $20 \times 10^{6}$ peripheral blood mononuclear cells (PBMCs) were seeded per $\mathrm{T}_{75}$ flask in 3 flasks and cultured in culture medium, as previously described [16]. The medium was refreshed twice a week and the cells were maintained at $37^{\circ} \mathrm{C}$ and $5 \% \mathrm{CO}_{2}$. At $60 \%$ confluency the cells were trypsinized with $0.25 \%$ trypsin-EDTA and subcultured until passage 3 in expansion medium, consisting of low glucose DMEM (Gibco), 20\% fetal bovine serum (Gibco) and $1 \%$ antibiotics - antimycotics (Sigma). The isolated cells were characterized as previously described [16]. At passage 3, the cells were trypsinized and resuspended in DMEM low glucose with $10 \%$ of dimethyl sulfoxide (DMSO, Sigma). At this point the VenoCell ${ }^{\circledR}$ was frozen overnight in isopropanol at $-80^{\circ} \mathrm{C}$. For the control group, 3 samples of DMEM with $10 \%$ DMSO were frozen in the same way. The samples were then stored in $-80^{\circ} \mathrm{C}$ and shipped on dry-ice before clinical application.

\section{Thawing and injecting mesenchymal stem cells (MSCs)}

Under field circumstances the thawing process is not always an easy job. Therefore, we decided to thaw the Veno-Cell ${ }^{\circledR}$ in the palm of our hand as a variation to a temperature-controlled warm water bath. At different time points, trypan blue stainings were performed in order to comparatively evaluate the viability of the cells in different conditions.

After thawing, the samples were diluted 1:50 in physiological saline solution $(\mathrm{NaCl} 0.9 \%)$ and slowly intravenously administered using a 21 Gauge $(\mathrm{G})$ needle measuring $40 \mathrm{~mm}$. Afterwards, the horses were closely monitored for 1 week by clinically examining them on daily basis (breathing, temperature, pulse, lymph nodes, mucosae). Particular attention was directed onto observing any possible adverse effect or hypersensitivity reaction, which would be noticeable in the form of wheal formation (physical reaction), sweating, strongly respiring or fever. The local ethical committee approved of the experimental design (EC_2012_001).

\section{Acceptor horses}

For the evaluation of different hematological parameters after placebo or Veno-Cell ${ }^{\circledR}$ injection, 6 acceptor horses were selected based on their age (>12-years-old), history of poor performance and general condition over longer than 6 months and gender (gelding).

Since it is known that different hematological parameters are affected by external influences, such as transport, training, stress, feeding, sampling time, etc., 3 control horses were injected with the carrier fluid consisting of DMEM and 10\% DMSO alone and different factors were strictly controlled in the present study. First of all, the horses were housed in their familiar stable and no transport was allowed during the entire study. Secondly, a tight feeding schedule was implemented which consisted of $1 \mathrm{~kg}$ of commercially available grain mixture and approximately $5 \mathrm{~kg}$ of hay at 7 a.m. and 5 p.m.. Finally, in order to avoid stress, the horses were kept in their stable during the blood sampling (at 10:30 a.m.) and the rest of the day, besides for the mild training program at 2 p.m. Sampling at the exact same time was important in order to exclude hematological parameter artifacts which were subject to the circadian rhythm and to avoid false interpretations that could arise hereby.

\section{Hematology}

In order to obtain the initial values of the different hematological parameters of the 6 horses, blood samples were collected in EDTA, citrate, glucose and serum tubes 1 week before and immediately before the injection (the average $=\mathrm{T}_{0}$, the basal values). The effects of the intravenous MSC injection was evaluated by sampling the horses after 1 day $\left(\mathrm{T}_{1}\right), 1$ week $\left(\mathrm{T}_{2}\right), 3$ weeks $\left(\mathrm{T}_{3}\right)$ and 2 months $\left(\mathrm{T}_{4}\right)$.

The following parameters were evaluated: (I) white blood cells: basophils, eosinophils, neutrophils, thrombocytes, lymphocytes and monocytes; (II) hormones: insulin and cortisol; (III) blood proteins: total protein and albumin; (IV) minerals: Iron, Sodium, Potassium, Chloride, Bicarbonate, Calcium and Magnesium; (V) metabolites: glucose; and (VI) enzymes: alkaline phosphatase. In addition, at 2 time points the antibody production was measured by following the levels of IgG, IgA and IgM (VII).

\section{Statistical analyses}

For the response variables that were assessed on both the treated and control group, the statistical analysis is based on the mixed model with horse as random effect and treatment (MSC or placebo), time $\left(\mathrm{T}_{1}, \mathrm{~T}_{2}, \mathrm{~T}_{3}\right.$ and $\left.\mathrm{T}_{4}\right)$ and their interaction as categorical fixed effects. The response variable corresponds to the difference of the outcome with that at baseline since the basal physiological values of each horse (before injection $=\mathrm{T}_{0}$ ) should be taken into account. In the absence of significant interaction, only the overall difference between treatment and control is reported and an F-test is used to compare treatment and control. In the presence of significant interaction, the treated and placebo group is compared at each of the 4 time points separately based on an F-test, using Bonferroni's adjustment method for multiple comparisons.

For IGF-I which was only assessed in the treated horses, the analysis is based on the mixed model with horse as random effect and time $\left(\mathrm{T}_{1}\right.$, $\mathrm{T}_{2}, \mathrm{~T}_{3}$ and $\mathrm{T}_{4}$ ) as categorical fixed effect. If time has a significant effect, an F-test is used to test whether there is a significant effect with baseline at each time point separately using Bonferroni's adjustment method for multiple comparisons. In the absence of a time effect, an F-test is used to test whether on average IGF-I levels differ from baseline. IgG, IgM and IgA levels are analysed by a paired t-test to compare $\mathrm{T}_{0}$ and $\mathrm{T}_{1}$.

All tests were performed at a global significance level of 5\% using SAS version 9.3 .

\section{Results}

\section{Isolation of mesenchymal stem cells (MSCs)}

After 17 days the first spindle shaped cells were noticed in the culture flasks and at 21 days after isolation the cells were trypsinized at approximately $60 \%$ confluency (Figure 1). The characterization experiments were performed as previously described [16] and revealed that the isolated cells fulfilled all the requirements to be typed as MSCs according to the proposed guidelines by Dominici et al. [17].

\section{Thawing and injecting mesenchymal stem cells (MSCs)}

It has been reported that frozen equine peripheral blood (PB)- 

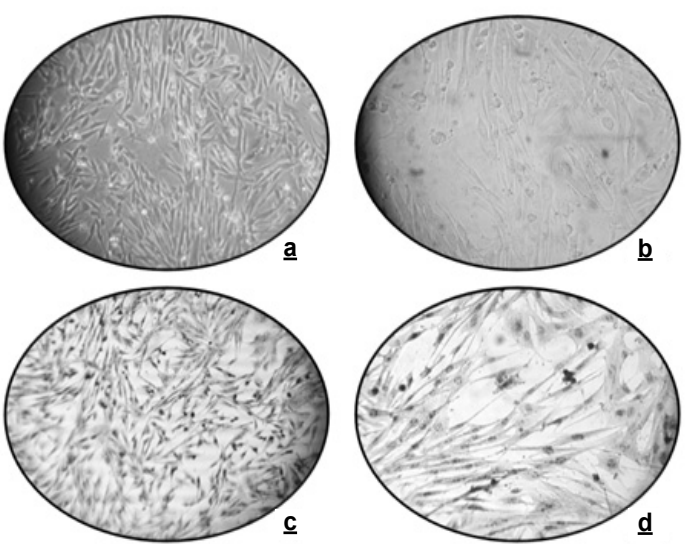

Figure 1: Representative images of peripheral blood (PB)-derived mesenchymal stem cells (MSCs): light microscopy at 20x (a) and 40x (b) magnification and after staining with haematoxylin at 20x (c) and 40x (d) magnification. Scale bars represent $50 \mu \mathrm{m}$.

derived mesenchymal stem cells (MSCs) possess the same stem cell characteristics as freshly isolated cells [18]. Moreover, fresh equine PB-derived MSCs dramatically decline in cell number after 12 hours of transport and have a higher risk to become senescent after 24 hours of transport [19]. In these regards, the use of frozen samples is justified and adds to the product shelf life. Thawing in the field is usually performed by keeping the sample in the palm of one's hand. In order to compare the effects of thawing cells in field and laboratory conditions, the cell viability was assessed after thawing in the palm of the hand and in a temperature-controlled warm water bath. Our data show that the manner of thawing did not determine the percentage of cell viability, since there were no considerable changes after thawing the cells in a hand $(92 \pm 2.1 \%)$ or in a warm water bath $(91 \pm 2.7 \%)$ (Figure 2). However, we should not fail to mention that the cell viability decreased within 30 minutes after palm-thawing $(84 \pm 5 \%)$ as well as warm water bath-thawing $(85 \pm 3.6 \%)$ (Figure 2$)$. After 1 hour the average viability was $80 \%$ for both thawing methods (Figure 2). The decrease in cell viability occurs due to the cytotoxic effect of DMSO and can be avoided in the laboratory by instantly washing the cells with medium. In the field, the DMSO effect can be circumvented by injecting the suspension immediately after thawing. Therefore in the present study the injection was performed within 10 minutes after thawing.

After the Veno-Cell ${ }^{\circledR}$ treatment, the horses were closely monitored and adverse effects could be noticed neither by the attending veterinarian nor by the caretakers.

\section{Hematological results}

In the control group, no considerable changes could be noticed before and after the DMEM and 10\% DMSO injection. On the other hand, the results of the different hematological parameters in the treated group showed the same evolution in all 3 horses. In comparison to the control group, only baseline adjusted blood thrombocyte levels varied differently over time in the treated and the control group, i.e. a significant interaction between time and treatment $(\mathrm{P}<0.001)$. At 1 day after the treatment $\left(\mathrm{T}_{1}\right)$, baseline adjusted blood thrombocyte levels were significantly higher in the treated group as compared to the control group $(\mathrm{P}<0.0001)$ (Figure 3$)$. Overall, the baseline adjusted cortisol levels $(\mathrm{P}=0.0490)$ and number of neutrophils $(\mathrm{P}=0.0042)$ were significantly higher in the treated group as compared to the control group (Table 1). The baseline adjusted blood glucose levels, on the other hand, were significantly lower in the treated group $(\mathrm{P}=0.033)$. Baseline adjusted basophils, eosinophils, lymphocytes and monocytes remained approximately the same in all the horses regardless the treatment (Table 1). Additionally, the levels of alkaline phosphatase, total protein, albumin, and all the tested minerals were not influenced by the MSC injections (Table 2).

Baseline adjusted insulin-like growth factor type-I (IGF-I) levels differed over time ( $\mathrm{P}=0.0199)$. No significant differences of the IGF-I levels were found when comparing with baseline when properly adjusting for multiple comparisons (Figure 4). In addition, the antibody levels were measured before and after the treatment as an indicator of the humoral immune response. No significant changes of the IgA, the IgM or the IgG could be detected after intravenous mesenchymal stem

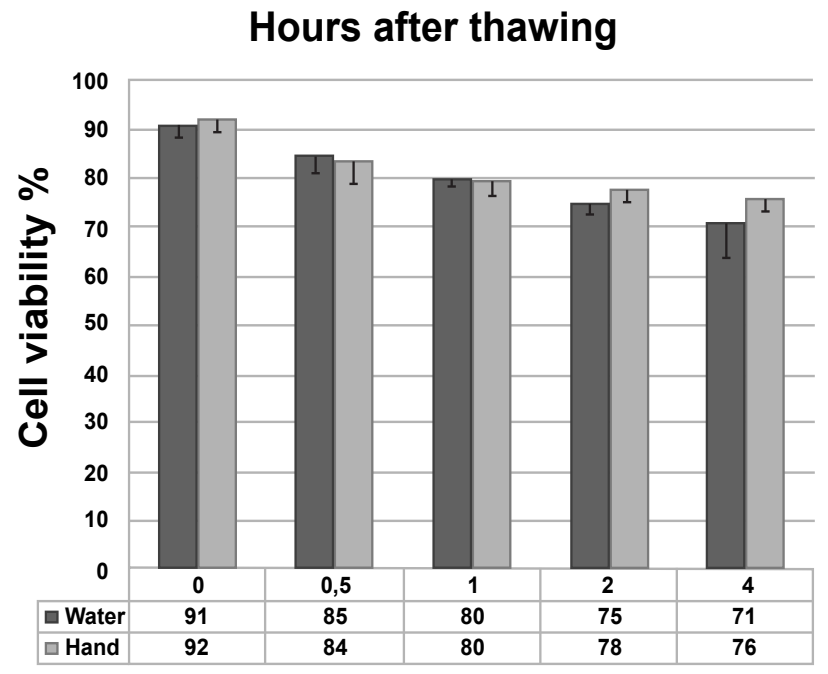

Figure 2: Palm-thawed peripheral blood (PB)-derived mesenchymal stem cells (MSCs) resulted in similar cell viability as in the samples thawed in temperature-controlled warm water bath. However, after 1 hour a cytotoxicity of approximately $20 \%$ was noticed under both circumstances.
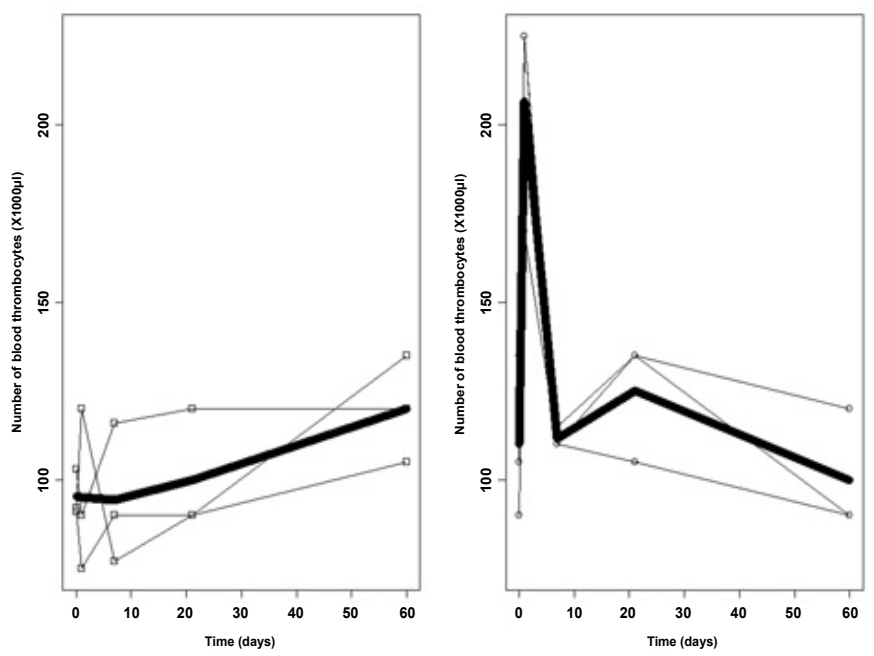

Figure 3: In contrast to the rather constant thrombocyte levels in the control group (left figure), a two-fold increase could be noticed at 1 day after the intravenous allogenic mesenchymal stem cell (MSC) injection $\left(T_{1}\right)$ (right figure). The narrow lines represent the different individuals, whereas the thick lines represent the average values. 


\begin{tabular}{|c|c|c|c|}
\hline PARAMETER & Control (se) & Treated (se) & P-value \\
\hline Cortisol ( $\mu \mathrm{g} / \mathrm{dl})$ & $0.34(0.36)$ & $1.75(0.36)$ & 0.049 \\
\hline Insulin (mU/I) & $-0.2(4.90)$ & $-3.65(4.90)$ & 0.645 \\
\hline Glucose (mg/dl) & $3.5(1.33)$ & $-2.5(1.33)$ & 0.033 \\
\hline Basophils (cells/ $\mu l)$ & $-5.92(12.73)$ & $-4.92(12.73)$ & 0.9584 \\
\hline Eosinophils (cells/ $\mu l)$ & $-3.75(25.08)$ & $-49(25.08)$ & 0.2711 \\
\hline Neutrophils (cells/ $\mu l)$ & $-226.92(142.65)$ & $446.5(142.65)$ & 0.0042 \\
\hline Lymphocytes (cells/ul) & $-162.33(132.09)$ & $-51.00(132.09)$ & 0.5833 \\
\hline 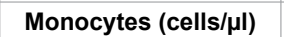 & $-3.58(30.14)$ & $45.25(30.14)$ & 0.3159 \\
\hline
\end{tabular}

Table 1: Different baseline adjusted hematological parameter estimates in the control and treated group. As there was no interaction between time and treatment for the hematological parameters reported in this table, the reported values correspond to the difference between the average over the different timepoints $\left(T_{1}\right.$, $\left.T_{2}, T_{3}, T_{4}\right)$ and the baseline $\left(T_{0}\right)$, with corresponding $P$-value for the null hypothesis that this difference is the same in the treated and control group.

\begin{tabular}{|c|c|c|c|}
\hline PARAMETER & Before Treatment & After Treatment & $\begin{array}{c}\text { Reference } \\
\text { Values }\end{array}$ \\
\hline $\begin{array}{c}\text { Alkaline Phosphatase } \\
\text { (U/l) }\end{array}$ & 459 & 433 & $<500$ \\
\hline Albumin (g/dl) & 3.4 & 3.4 & $2.5-4.4$ \\
\hline Total Protein (g/dl) & 6.7 & 6.8 & $5.8-7.7$ \\
\hline Iron ( $\mathbf{m g} / \mathbf{d} \mathbf{l})$ & 156 & 155 & $75-240$ \\
\hline Sodium (meq/l) & 138 & 138 & $134-150$ \\
\hline Potassium (meq/l) & 3.5 & 3.6 & $2.8-5.8$ \\
\hline Chloride (meq/l) & 99 & 101 & $94-105$ \\
\hline Calcium (meq/l) & 11.9 & 12.0 & $9.6-13.3$ \\
\hline Magnesium (meq/l) & 2.1 & 2.1 & $1.5-2.4$ \\
\hline
\end{tabular}

Table 2: Average haematological values of the treated group before and after Veno-Cell ${ }^{\circledR}$ administration.

cell (MSC) injection, indicating a low short-term immunogenicity of allogenic MSCs.

\section{Discussion}

In the present study, we have evaluated the effects of allogenic peripheral blood (PB)-derived mesenchymal stem cells (MSCs) (Veno$\mathrm{Cell}^{\mathbb{R}}$ ) on the hematological status of horses. In all the patients the same changes were noticed in their blood at different time points after intravenous injection. One might postulate that the significant increase in thrombocytes or cortisol in all 3 treated horses was due to a reactive thrombocytosis or temporary hypercortisolism which might occur in stress circumstances. However, the horses were sampled several times before the single injection of Veno-Cell ${ }^{\circledR}$ without an increase in their hematological parameters and also the control horses did not reveal any changes in their blood values after the control injection of DMEM and $10 \%$ DMSO. Nevertheless, in order to state that the changes noticed in the present study were attributable to the communicative effects of MSCs or to their epitope expression needs further investigation. In any case, the observed thrombocytosis implicates bone marrow activation within the acceptor horses after the allogenic MSC injection. Indeed, undifferentiated marrow blasts have been previously associated with an augmentation of the thrombocyte levels as well [20].

Different in vitro studies report that MSCs inhibit the innate immune activation by blocking dendritic cell maturation and suppressing monocyte and T-cell activity with a significant tumor necrosis factor-alfa (TNF- $\alpha$ ) and interleukin (IL)-6 reduction [2125]. Furthermore, MSCs would also increase the in vitro production of agents such as IL-1 receptor antagonist [25] and IL-10 [26], which directly block inflammatory signaling. Indeed, in the present study, besides the increase in neutrophil levels, no changes in cellular or humoral immunity parameters could be noticed. However, the MSCrelated inhibition of TNF- $\alpha$ would lead to an increase of insulin-like growth factor type-I (IGF-I) [27], whereas our data show a substantial decrease in IGF-I. Indeed, the basal level of IGF-I was determined before injection and it was clear that the MSC injection caused a one week decline in IGF-I in the treated group. This is a remarkable finding, since IGF-I has a positive effect on somatic growth and stimulates regeneration of different organs and tissues, such as liver and skeletal muscles [28-30] and a decrease of IGF-I is usually seen in patients with chronic inflammation (TNF- $\alpha$ and IL-1 increase) [31,32]. We have postulated 3 possible explanations for this discrepancy. First, a possibility exists that MSCs are not able to inhibit TNF- $\alpha$ production in vivo. Secondly, the documented increase in thrombocytes (accompanied with platelet-derived growth factor (PDGF) production) are capable of inhibiting the IGF-I production, as previously reported in rat bone cell cultures [33]. Finally, it is probable that the increased cortisol levels had an inhibitory effect on IGF-I, as previously described in humans [34]. Apparently, both the second and the third hypothesis answer the question of the reduced IGF-I, since the increase in thrombocytes and cortisol levels were noticed at exactly the same time point as the time of decrease in IGF-I production. Nevertheless, this is a perfect example on how the complexity of in vivo studies increases along with the number of players considered. These unexpected results might lead to the optimization of the therapy. Indeed, MSCs could be stimulated in vitro before an in vivo application. In this regard, it has been described that pretreating MSCs with TNF- $\alpha$ could cause an increase in IGF-I production [35]. Nevertheless, future research will have to determine whether or not this remains the case after intravenous application.

Additionally, insulin and glucose levels decreased after the allogenic MSC injection. This was no surprise, since the inhibitory effect of cortisol (significant increase) on insulin has been previously reported [36]. Moreover, the rise in cortisol levels remained noticeable for 2 more months. This might explain how non-HLA (human

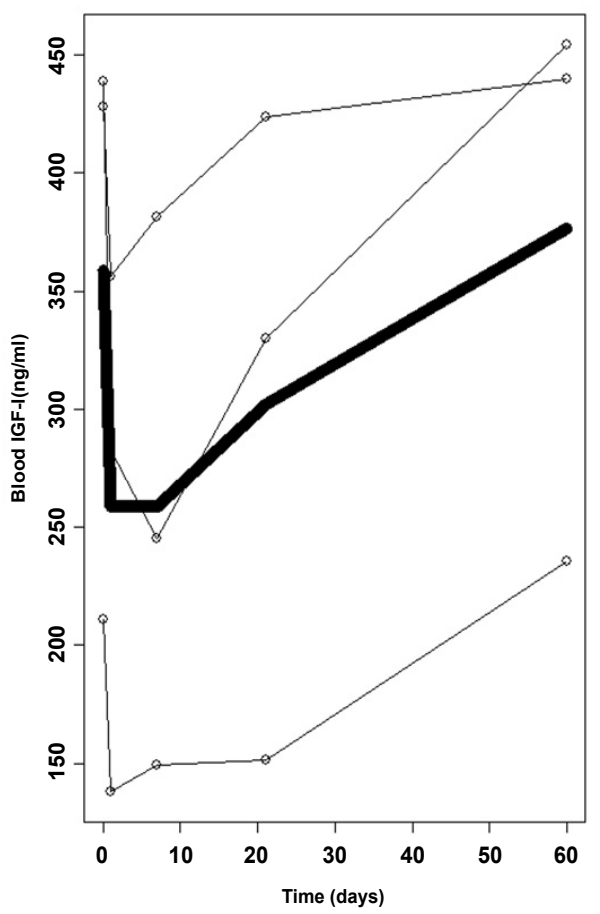

Figure 4: A decrease in insulin-like growth factor type-I could be noticed from 1 day until 1 week after the intravenous allogenic mesenchymal stem cell (MSC) injection $\left(T_{1-2}\right)$. The narrow lines represent the different individuals, whereas the thick lines represent the average values. 
Citation: Broeckx S, Forier R, Mariën T, Suls M, Savkovic V, et al. (2013) The Influence of Allogenic Mesenchymal Stem Cells on the Hematological Status of Horses. J Stem Cell Res Ther 3: 136. doi:10.4172/2157-7633.1000136

Page 5 of 6

leukocyte antigen) matched MSC infusions might reduce graft failure of hematopoietic stem cells [37] and organ transplantation [13,15]. Moreover, communication with the owners revealed that the horses were in good shape and no adverse effects were noticed after the MSC injection. Since it has been reported that changes in blood cortisol levels have an influence on the individual's performance level [38], the cortisol increase after intravenous MSC therapy might have a similar effect. However, further research is definitely warranted in order to verify whether or not MSCs might be used as a performance enhancing tool.

In conclusion, the present study is the first one in describing the influence of allogenic PB-derived MSCs (Veno-Cell ${ }^{\circledR}$ ) on the hematological status of horses.

\section{Author Disclosure Statement}

The authors declare competing financial interests in Global Stem cell Technology.

\section{Acknowledgements}

The authors would like to acknowledge Global Stem cell Technology and the sources of private funding that have provided the basis for this study. Moreover, the authors would like to thank Nathalie and Jo Gijbels for their technical assistance. In addition, the Federal Public Service of Health should be acknowledged for providing GST with a laboratory recognition number (LA1700607), allowing us to perform this study.

\section{References}

1. Choi MY, Yeo SW, Park KH (2012) Hearing restoration in a deaf animal mode with intravenous transplantation of mesenchymal stem cells derived from human umbilical cord blood. Biochem Biophys Res Commun 427: 629-636

2. Oh JY, Lee RH, Yu JM, Ko JH, Lee HJ, et al. (2012) Intravenous mesenchymal stem cells prevented rejection of allogeneic corneal transplants by aborting the early inflammatory response. Mol Ther 20: 2143-2152

3. Riordan NH, Ichim TE, Min WP, Wang H, Solano F, et al. (2009) Non-expanded adipose stromal vascular fraction cell therapy for multiple sclerosis. J Trans Med 7: 29

4. Marfe G, Massaro-Giordano M, Ranalli M, Cozzoli E, Di Stefano C, et al (2011) Blood Derived Stem Cells: An Ameliorative Therapy in Veterinary Ophthalmology. J Cell Physiol 227: 1250-1256

5. Spaas JH, Broeckx S, Van de Walle GR, Polettini M (2013) The effects of equine peripheral blood stem cells (PBSC) on cutaneous wound healing: a clinical evaluation in four horses. Clin Exp Dermatol 38: 280-284

6. Spaas JH, Gambacurta A, Polettini M, Broeckx S, Van Hoeck F, et al. (2011) Purification and expansion of stem cells from equine peripheral blood, with clinical applications. Vlaams Diergeneesk Tijdschr 80: 129-135.

7. Kode JA, Mukherjee S, Joglekar MV, Hardikar AA (2009) Mesenchymal stem cells: immunobiology and role in immunomodulation and tissue regeneration. Cytotherapy 11: 377-391.

8. Zhang J, An Y, Gao LN, Zhang YJ, Jin Y, et al. (2012) The effect of aging on the pluripotential capacity and regenerative potential of human periodontal ligament stem cells. Biomaterials 33: 6974-6986.

9. Beerts C, Seifert C, Zimmerman M, Felix E, Suls M, et al. (2013) Desmitis of the accessory ligament of the sequine deep digital flexor tendon: a regenerative approach. J Tissue Sci Eng. Accepted for publication.

10. Broeckx S, Zimmerman M, Aerts D, Seys B, Suls M, et al. (2012) Tenogenesis of equine peripheral blood-derived mesenchymal stem cells: in vitro versus in vivo. J Tissue Sci Eng S11-001: 1-6.

11. Carrade DD, Affolter VK, Outerbridge CA, Watson JL, Galuppo LD, et al. (2011) Intradermal injections of equine allogeneic umbilical cord-derived mesenchymal stem cells are well tolerated and do not elicit immediate or delayed hypersensitivity reactions. Cytotherapy 13: 1180-1192.

12. Carrade DD, Owens SD, Galuppo LD, Vidal MA, Ferraro GL, et al. (2011) Clinicopathologic findings following intra-articular injection of autologous and allogeneic placentally derived equine mesenchymal stem cells in horses. Cytotherapy 13: 419-430

13. Fang BJ, Song YP, Lin QD, Zhang YL, Cao Y, et al. (2007) Human adipose tissue-derived mesenchymal stromal cells as salvage therapy for treatment of severe refractory acute graft-vs.-host disease in two children. Pediatr Transplant 11: 814-817.

14. Guest DJ, Smith MR, Allen WR (2008) Monitoring the fate of autologous and allogeneic mesenchymal progenitor cells injected into the superficial digital flexor tendon of horses: preliminary study. Equine Vet J 40: 178-181.

15. Ringden O, Uzunel M, Rasmusson I, Remberger M, Sundberg B, et al. (2006) Mesenchymal stem cells for treatment of therapy-resistant graft-versus-host disease. Transplantation 81: 1390-1397.

16. Spaas JH, Schauwer CD, Cornillie P, Meyer E, Soom AV, et al. (2013) Culture and characterisation of equine peripheral blood mesenchymal stromal cells. Vet J 195: 107-113.

17. Dominici M, Le Blanc K, Mueller I, Slaper-Cortenbach I, Marini F, et al. (2006) Minimal criteria for defining multipotent mesenchymal stromal cells. The International Society for Cellular Therapy position statement. Cytotherapy 8 315-317.

18. Martinello T, Bronzini I, Maccatrozzo L, lacopetti I, Sampaolesi M, et al. (2010) Cryopreservation does not affect the stem characteristics of multipotent cells isolated from equine peripheral blood. Tissue Engineering Part C: Methods 16: 771-781.

19. Bronzini I, Patruno M, lacopetti I, Martinello T (2012) Influence of temperature time and different media on mesenchymal stromal cells shipped for clinical application. Vet J 194: 121-123.

20. Schnittger S, de Sauvage FJ, Le Paslier D, Fonatsch C (1996) Refined chromosomal localization of the human thrombopoietin gene to 3q27-q28 and exclusion as the responsible gene for thrombocytosis in patients with rearrangements of 3q21 and 3q26. Leukemia 10: 1891-1896

21. Djouad F, Charbonnier LM, Bouffi C, Louis-Plence P, Bony C, et al. (2007) Mesenchymal stem cells inhibit the differentiation of dendritic cells through an interleukin-6-dependent mechanism. Stem Cells 25: 2025-2032.

22. English K, Barry FP, Mahon BP (2008) Murine mesenchymal stem cells suppress dendritic cell migration, maturation and antigen presentation Immunol Lett 115: 50-58.

23. Di Nicola M, Carlo-Stella C, Magni M, Milanesi M, Longoni PD, et al. (2002) Human bone marrow stromal cells suppress T-lymphocyte proliferation induced by cellular or nonspecific mitogenic stimuli. Blood 99: 3838-3843.

24. Nasef A, Chapel A, Mazurier C, Bouchet S, Lopez M, et al. (2007) Identification of IL-10 and TGF-beta transcripts involved in the inhibition of T-lymphocyte proliferation during cell contact with human mesenchymal stem cells. Gene Expr 13: 217-226.

25. Ortiz LA, DuTreil M, Fattman C, Pandey AC, Torres G, et al. (2007) Interleukin 1 receptor antagonist mediates the antiinflammatory and antifibrotic effect of mesenchymal stem cells during lung injury. Proc Nati Acad of Sci U S A 104 11002-11007.

26. Nemeth K, Leelahavanichkul A, Yuen PST, Mayer B, Parmelee A, et al. (2009) Bone marrow stromal cells attenuate sepsis via prostaglandin $E(2)$-dependent reprogramming of host macrophages to increase their interleukin-10 production. Nat Med 15: 42-49.

27. Lang $\mathrm{CH}$, Nystrom G, Frost RA (2008) Beta-adrenergic blockade exacerbate sepsis-induced changes in tumor necrosis factor alpha and interleukin-6 in skeletal muscle and is associated with impaired translation initiation. J Trauma 64: 477-486.

28. Charvet C, Houbron C, Parlakian A, Giordani J, Lahoute C et al. (2006) New role for serum response factor in postnatal skeletal muscle growth and regeneration via the interleukin 4 and insulin-like growth factor 1 pathways. Mol Cell Biol 26: 6664-6674.

29. Elis S, Wu Y, Courtland HW, Cannata D, Sun H, et al. (2011) Unbound (bioavailable) IGF1 enhances somatic growth. Dis Model Mech 4: 649-658.

30. Hijikawa T, Kaibori M, Uchida Y, Yamada M, Matsui K, et al. (2008) Insulin-like growth factor 1 prevents liver injury through the inhibition of TNF-alpha and iNOS induction in D-galactosamine and LPS-treated rats. Shock 29: 740-747.

31. Savastano S, Di Somma C, Pizza G, De Rosa A, Nedi V, et al. (2011) Liver- 
Citation: Broeckx S, Forier R, Mariën T, Suls M, Savkovic V, et al. (2013) The Influence of Allogenic Mesenchymal Stem Cells on the Hematological Status of Horses. J Stem Cell Res Ther 3: 136. doi:10.4172/2157-7633.1000136

spleen axis, insulin-like growth factor-(IGF)-I axis and fat mass in overweight/ obese females. J Transl Med 9: 136

32. Pierce AL, Breves JP, Moriyama S, Hirano T, Grau EG (2011) Differential regulation of Igf1 and Igf2 mRNA levels in tilapia hepatocytes: effects of insulin and cortisol on GH sensitivity. J Endocrinol 211: 201-210.

33. Canalis E, Pash J, Gabbitas B, Rydziel S, Varghese S (1993) Growth factors regulate the synthesis of insulin-like growth factor-I in bone cell cultures. Endocrinology 133: 33-38.

34. Sartorio A, Agosti F, Patrizi A, Gattico A, Tringali G, et al. (2012) GH and Cortisol Responses Following an Acute Session of Respiratory Muscle Endurance Training in Severely Obese Patients. Horm Metab Res 45: 239-244.
35. Crisostomo PR, Wang Y, Markel TA, Wang M, Lahm T, et al. (2008) Human mesenchymal stem cells stimulated by TNF-alpha, LPS, or hypoxia produce growth factors by an NF kappa B- but not JNK-dependent mechanism. Am J Physiol Cell Physiol 294: C675-682.

36. Brown DF and Brown DD (2003) USMLE Step 1 Secrets: Questions You Will Be Asked on USMLE Step 1. (Belfus, P.H., ed): 63.

37. Le Blanc K, Samuelsson H, Gustafsson B, Remberger M, Sundberg B, et al (2007) Transplantation of mesenchymal stem cells to enhance engraftment of hematopoietic stem cells. Leukemia 21: 1733-1738.

38. Mujika I, Padilla S, Pyne D, Busso T (2004) Physiological changes associated with the pre-event taper in athletes. Sports Med 34: 891-927. 